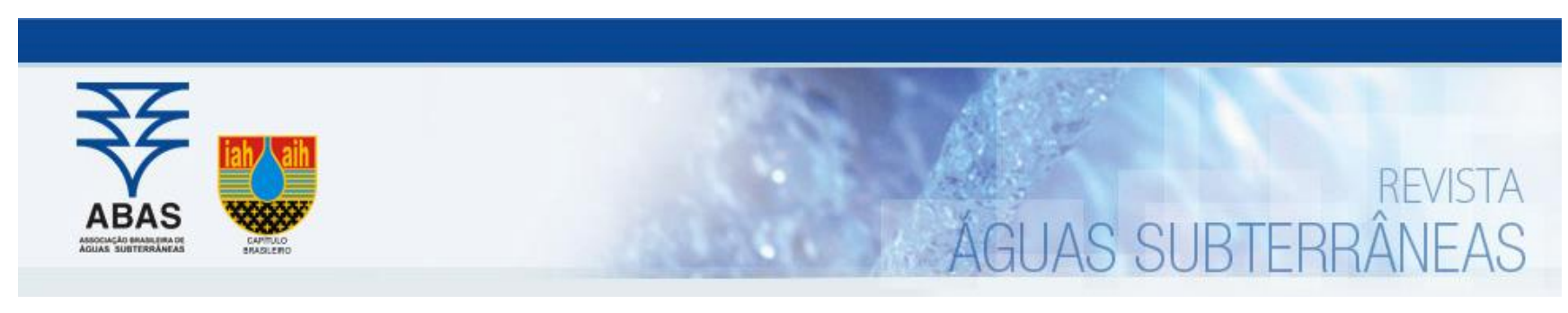

Artigos

\title{
Efeito da interpolação de dados hidrogeológicos em aquíferos sedimentares: estudo de caso no estado do Paraná
}

\section{Effect of the interpolation of hydrogeological data in sedimentary aquifers: a case study in the state of Paraná}

\author{
Paula Gabriela Leal Hernandez ${ }^{1}$; Gustavo Barbosa Athayde1; Camila de Vasconcelos Muller Athayde1; Otavio Augusto Boni \\ Licht $^{1}$ \\ 1 Universidade Federal do Paraná (UFPR), Laboratório de Pesquisas Hidrogeológicas (LPH). Curitiba, PR
}

$\bowtie$ pglhernandez@gmail.com, gustavo.athayde@ufpr.br, camilavmuller@ufpr.br, otavio.licht@gmail.com

\section{Palavras-chave: \\ Análise espacial. \\ Hidrogeologia. \\ Bacia do Paraná. \\ Bacia Bauru.}

\begin{abstract}
Resumo
A água subterrânea é de grande importância como reserva hídrica e o uso de Sistemas de Informações Geográficas tem se mostrado eficaz para a compreensão da ocorrência e movimentação deste recurso. 0 objetivo do estudo foi avaliar métodos de interpolação aplicados a dados hidrogeológicos com a verificação do impacto gerado pelo processo de estimativa. Os métodos avaliados foram os interpoladores Inverso da Distância Ponderada, Triangulação e Topo to Raster e os dados considerados foram os parâmetros hidrogeológicos dos aquíferos sedimentares no estado do Paraná: Furnas, Itararé, Rio Bonito, Passa Dois, Guarani e Caiuá. Os resultados foram avaliados de acordo com a ocorrência de estimativas positivas e negativas, normalized root mean square e precisão do interpolador ao gerar resultados mais próximos dos valores observados. Esse estudo mostrou o efeito da interpolação em dados hidrogeológicos indicando que o Inverso da Distância Ponderada foi o método mais adequado para os parâmetros e aquíferos focos do estudo, pois apresentou as menores variações entre os valores observados e os estimados e os menores valores de normalized root mean square (entre 0 e 0,108). Esse estudo demonstra a importância em escolher o método adequado para intepretação de dados em regiões não amostradas devido às grandes variações em interpolar dados.
\end{abstract}

Keywords:

Spatial analysis.

Hydrogeology.

Paraná Basin.

Bauru Basin.

Revisão por pares.

Recebido em: 12/06/2020.

Aprovado em: 28/10/2020.

\begin{abstract}
Groundwater is of great importance as a water reserve, and the use of Geographic Information Systems has been shown to be useful in understanding the occurrence and movement of this resource. The study's objective was to evaluate interpolation methods applied to hydrogeological data with the verification of the impact generated by the estimation process. The methods evaluated were the Inverse distance weighting, Triangulation and Topo to Raster, and the data considered were hydrogeological parameters of the sedimentary aquifers in the state of Paraná: Furnas, Itararé, Rio Bonito, Passa Dois, Guarani, and Caiuá. The results were evaluated according to the occurrence of positive and negative estimates, normalized root mean square, and precision of the interpolator when generating results closer to the observed values. This study showed the effect of interpolation on hydrogeological data, indicating the Inverse distance weighting was the most appropriate method for the parameters and aquifer foci of the study, as it presented smaller variations between the observed values and the estimated and lower normalized root mean values square (between 0 and 0.108). This study demonstrates the importance of choosing the appropriate method for interpreting data in non-sampled regions due to the large variations in interpolating data.
\end{abstract}

DOI: http:/dx.doi.org/10.14295/ras.v35i1.29911

\section{INTRODUÇÃO}

O uso de Sistemas de Informações Geográficas (SIG) tem se mostrado eficaz para compreensão da ocorrência e movimentação da água subterrânea, visto a variedade de trabalhos que têm empregado técnicas de geoprocessamento para essa finalidade (e.g. RIBEIRO et al., 2010; KUMAR et al., 2016; PINTO et al., 2017). Porém, estudos que avaliam o efeito da interpolação em dados hidrogeológicos são escassos (e.g. ESTAVARENGO, 2017) e não foram encontrados no estado do
Paraná.

Obter informações hidrodinâmicas por meios convencionais em estudos geológicos e hidrogeológicos de campo (FEITOSA et al., 2008) nem sempre permite observar os variados fatores que controlam a ocorrência da água subterrânea, pois esse conhecimento é pontual (poços tubulares, piezômetros e nascentes) ou linear (cursos d'água). Com isso, as ferramentas em SIG têm se mostrado eficazes para estudos nessa área, possibilitando a análise espacial e realização de atividades de 
geoprocessamento, a fim de compreender o comportamento hidrogeológico em regiões não amostradas.

O objetivo do estudo é a comparação de três métodos de interpolação (Inverso da distância ponderada, Triangulação e Topo to Raster) em parâmetros hidrogeológicos dos aquíferos sedimentares no estado do Paraná, para identificar qual método de interpolação melhor se adequa aos dados desses aquíferos.

Algumas considerações devem ser observadas ao se interpolar dados hidrogeológicos:

- Parâmetros hidrogeológicos não são processos estacionários, pois variam ao longo do tempo;

- Geologia em subsuperfície, estruturas geológicas, fatores climáticos e geomorfológicos influenciam em toda sua dinâmica hídrica.

O que se observa com os resultados desse trabalho é que localmente ocorrem grandes variações nos valores observados e as duas afirmações citadas devem ser avaliadas quando estudos locais forem feitos.

Os métodos de interpolação são ferramentas de grande importância para o estudo de variáveis espaciais, contribuindo para o entendimento do comportamento de parâmetros hidrogeológicos. Espacializar esses dados é uma importante etapa para gerenciar os recursos hídricos subterrâneos e assim ter um melhor planejamento frente às ocorrências desses recursos.

\section{2. ÁREA DE ESTUDO}

A área de estudo está localizada na região hidrográfica do Paraná, que é uma região de grande desenvolvimento econômico e com a maior densidade populacional do país (IBGE, 2020), além de possuir as maiores demandas por recursos hídricos (ANA, 2014). Os aquíferos sedimentares em estudo estão localizados no estado do Paraná e são: Furnas, Itararé, Rio Bonito, Passa Dois, Guarani e Caiuá (Figura 1)

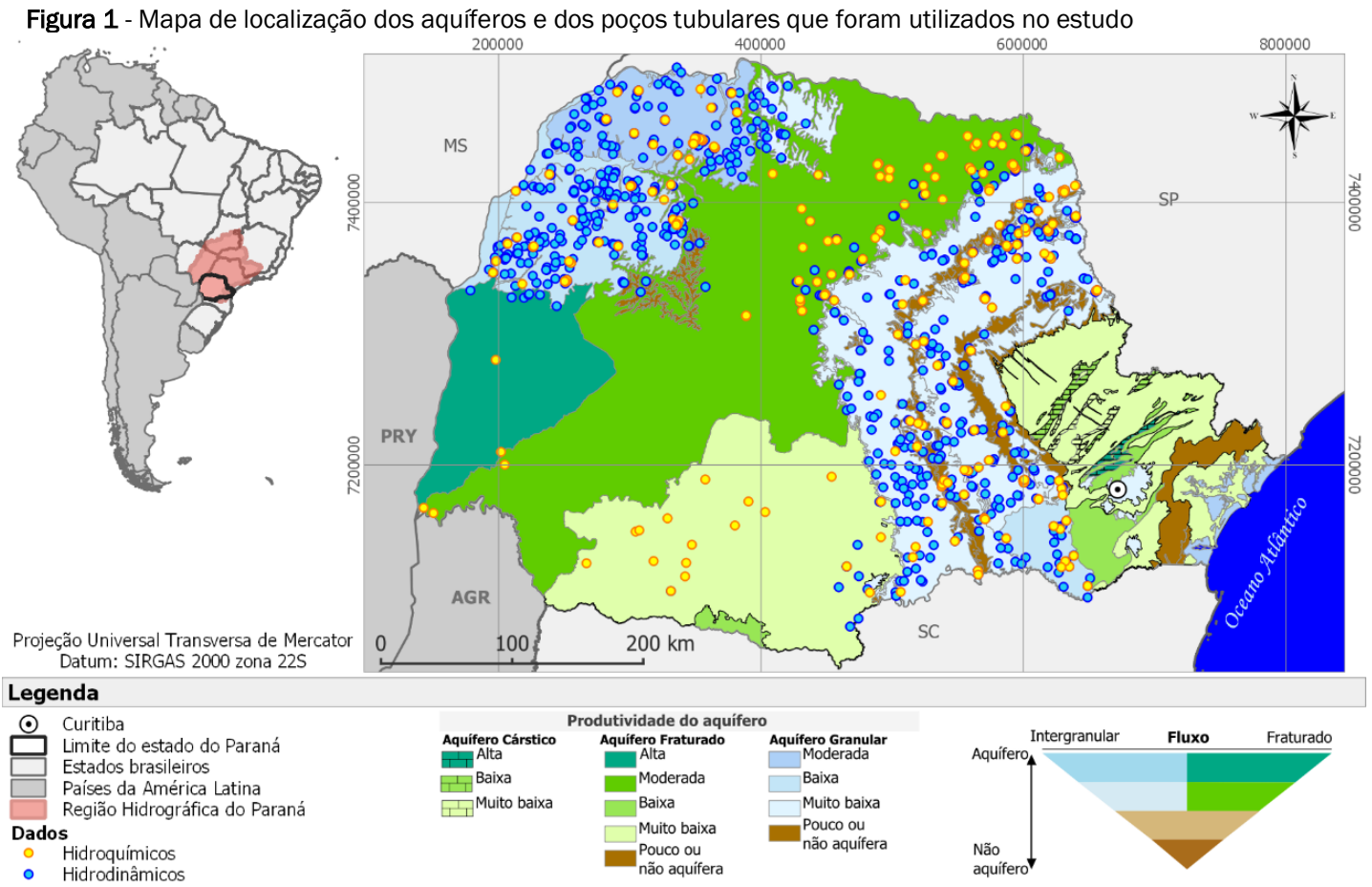

Fonte: Modificado de BRASIL (2005); Diniz et al. (2015); Struckmeier \& Margat (1995).

\section{CONTEXTO GEOLÓGICO E HIDROGEOLÓGICO}

As unidades geológicas da Bacia do Paraná correspondem às rochas formadas em grandes ciclos transgressivos-regressivos de idade Paleozoica e unidades continentais mesozoicas com rochas ígneas associadas (MILANI et al., 2007). Após o vulcanismo Serra Geral, durante o Cretáceo, foram criadas condições de sedimentação distintas da evolução geológica da Bacia do Paraná (FERNANDES, 1992). A nova acumulação de sedimentos ocorreu na região centro-meridional da Plataforma Sul-Americana, em uma bacia denominada Bacia
Bauru, de idade neocretácea (FERNANDES, 1992). Nesse contexto geológico estão inseridas as rochas que compõem os aquíferos em estudo.

\subsection{Aquífero Furnas}

O Aquífero Furnas é composto principalmente por arenitos de granulometria média a grossa e possui espessura em subsuperfície de até $300 \mathrm{~m}$ e em superfície de até $200 \mathrm{~m}$ (SCHNEIDER et al., 1974). Esse aquífero possui vazão mediana de $8,03 \mathrm{~m}^{3} / \mathrm{h}$ e nível d'água entre 1,48 e 107,32 m (BRASIL, 
2015). A particularidade desse aquífero é que, ao mesmo tempo em que ele é um aquífero sedimentar, localmente confinado pelas rochas da Formação Ponta Grossa, ele é tido como aquífero fraturado e localmente apresenta feições cársticas não carbonáticas (MELO et al., 2015). As águas desse aquífero são classificadas como bicarbonatadas cálcicas em sua maioria, no entanto, secundariamente, ocorrem classificações de águas bicarbonatadas sódicas, bicarbonatadas sódio-cálcicas e bicarbonatadas cálcio-sódicas (ROSA FILHO et al., 2011; BRASIL, 2015).

\subsection{Aquífero Itararé}

O Aquífero Itararé é composto por uma alternância de formações geológicas de arenitos, siltitos e lamitos, e possuem uma espessura de até $1.300 \mathrm{~m}$ (FRANÇA; POTTER, 1988). Esse aquífero possui vazão mediana de $7,70 \mathrm{~m}^{3} / \mathrm{h}$ e nível d'água entre 0,40 e 174,90 m (BRASIL, 2015). A característica marcante desse aquífero está em sua variação lateral, tanto dos arenitos como dos pelitos (ROSA FILHO et al., 2011). As águas desse aquífero são classificadas como bicarbonatadas cálcicas em sua maioria, seguidas por águas bicarbonatadas sódicas (BRASIL, 2015).

\subsection{Aquífero Rio Bonito}

O aquífero Rio Bonito é composto por arenitos, argilitos e areno-argilitos, ocorrendo nesse último os principais leitos de carvão na Bacia do Paraná, e sua espessura em superfície é de até $300 \mathrm{~m}$ (SCHNEIDER et al., 1974). Esse aquífero possui vazão mediana de $10 \mathrm{~m}^{3} / \mathrm{h}$ e nível d'água entre 0,65 e 194,85 m (BRASIL, 2015). As águas desse aquífero são classificadas como bicarbonatadas sódicas em sua maioria, seguidas por águas bicarbonatadas cálcicas e bicarbonatadas cálcio-sódicas (BRASIL, 2015).

\subsection{Aquífero Passa Dois}

O Aquífero Passa Dois é composto por argilitos, folhelhos e siltitos, associados a níveis de calcários, onde a maior espessura registrada é de $318 \mathrm{~m}$ (SCHNEIDER et al., 1974). Esse aquífero possui vazão mediana de $7,00 \mathrm{~m}^{3} / \mathrm{h}$ e nível d'água entre 0,59 e 81 m (BRASIL, 2015). Esse aquífero é o de menor potencialidade hídrica dentre os aquíferos em estudo, tendo sido considerado em trabalhos anteriores como aquiclude. Devido a intrusões de diques de diabásio, é possível a extração de água subterrânea por meio de poços tubulares nos espaços vazios junto às encaixantes (ROSA FILHO et al., 2011). As águas desse aquífero são classificadas como bicarbonatadas sódicas, seguidas por bicarbonatadas cálcio-sódicas e uma bicarbonatadas sódico-cálcicas (BRASIL, 2015).

\subsection{Aquífero Guarani}

O Aquífero Guarani é um imenso aquífero composto por rochas das formações Piramboia e Botucatu, de idades triássicas e juro-eocretáceas (CETESB, 2020). Esse aquífero atravessa fronteiras internacionais, além de atravessar a fronteira de outros sete estados brasileiros: Mato Grosso, Mato Grosso do Sul, Goiás, Minas Gerais, São Paulo, Rio Grande do Sul e Santa Catarina (CETESB, 2020). O Aquífero Guarani é do tipo livre na região aflorante, no entanto, sua maior extensão está confinada pelas rochas do Grupo Serra Geral, sendo constituído ainda por uma série de reservatórios, reflexo da junção de estruturas geológicas e intrusões de rochas básicas a intermediárias (ROSA FILHO et al., 2011). As rochas desse aquífero são arenitos finos a médios e localmente ocorrem arenitos argilosos e arenitos grossos a conglomeráticos, e a espessura varia de $50 \mathrm{~m}$ a $800 \mathrm{~m}$ (SCHNEIDER et al., 1974). Esse aquífero possui vazão mediana de $40,00 \mathrm{~m}^{3} / \mathrm{h}$ e nível d'água entre 0,50 e 234,7 m (BRASIL, 2015). As águas desse aquífero são classificadas como bicarbonatadas cálcicas predominantemente, seguidas por águas bicarbonatadas sódicas (BRASIL, 2015). No entanto, ocorre uma grande variabilidade devido ao grau de confinamento do aquífero, passando da predominância de águas bicarbonatadas cálcicas e bicarbonatadas sódicas a sulfatadas sódicas à medida que migram das zonas de baixo até alto confinamento (ROSA FILHO et al., 2011).

\subsection{Aquífero Caiuá}

O Aquífero Caiuá é um aquífero livre e localmente semiconfinado, e a água subterrânea é encontrada em camadas arenosas, onde suas maiores espessuras refletem o maior potencial de armazenamento (ROSA FILHO et al., 2011). Ele é composto por arenitos de granulometria muito fina a fina, com maior espessura registrada de 277 m (FERNANDES; COIMBRA, 2000). Esse aquífero possui vazão mediana de $10,00 \mathrm{~m}^{3} / \mathrm{h}$ e nível d'água entre 0,75 e 83,35 m (BRASIL, 2015). As águas desse aquífero são classificadas como bicarbonatadas cálcicas predominantemente, seguida por águas bicarbonatadas magnesianas (BRASIL, 2015).

\section{MATERIAIS E MÉTODOS}

Essa pesquisa apresenta a seguinte ordem: a) análise estatística dos dados; b) espacialização em ambiente SIG (Sistema de Informações Geográficas); c) interpolação dos parâmetros utilizando os interpoladores propostos; d) análise e discussão do método de interpolação mais adequado dentre os aplicados.

\subsection{Base de dados}

A base de dados foi obtida por meio da Carta das Águas Subterrâneas do Paraná (BRASIL, 2015), composta por um conjunto de documentos - mapas, relatórios e banco de dados em ambiente de Sistema de Informações Geográficas (SIG) dos aquíferos no estado do Paraná.

Os dados utilizados no estudo são de 845 poços tubulares profundos distribuídos nos aquíferos Furnas, Itararé, Rio Bonito, Passa Dois, Guarani e Caiuá, e os parâmetros utilizados são: capacidade específica $\left(\left(\mathrm{m}^{3} / \mathrm{h}\right) / \mathrm{m}\right)$, condutividade hidráulica $(\mathrm{m} / \mathrm{s})$, espessura saturada (metros), nível estático (metros), transmissividade $\left(\mathrm{m}^{2} / \mathrm{s}\right)$ e vazão $\left(\mathrm{m}^{3} / \mathrm{h}\right)$. A quantidade de poços e de amostras em cada um dos aquíferos pode ser observada na Tabela 1. 
Tabela 1 - Quantidade de poços tubulares profundos em cada aquífero. Fonte dos dados: BRASIL (2015)

\begin{tabular}{cc}
\hline Unidade aquífera & Quantidade de poços tubulares profundos \\
\hline Furnas & 36 \\
Itararé & 169 \\
Rio Bonito & 61 \\
Passa Dois & 95 \\
Guarani & 80 \\
Caiuá & 404 \\
Total & 845 \\
\hline
\end{tabular}

\subsection{Interpolação de dados hidrogeológicos}

A razão de analisar o erro nas interpolações, a porcentagem e representação espacial das regiões/poços que apresentaram maiores variações é para se entender qual o efeito da interpolação em dados hidrogeológicos. Os interpoladores utilizados são tidos na literatura como interpoladores exatos, no entanto, a distribuição espacial irregular dos poços e a variabilidade dos dados no espaço influencia a exatidão do processo. Os métodos de estimativa escolhidos estão disponíveis em dois softwares. Para interpolação utilizando os métodos Triangulação e Inverso da Distância Ponderada foi utilizada o SIG QGIS 2.18 e para a interpolação utilizando o método Topo to Raster foi utilizado o SIG Arcgis 10.6.1 (código da licença: 7765170259). Esses métodos foram escolhidos por utilizarem três métodos distintos de interpolação:

- $\quad$ No método Inverso da Distância Ponderada (Inverse distance weighting - IDW), são atribuídos pesos aos pontos amostrados de acordo com a distância que estão do ponto com valor desconhecido. 0 principal fator que afeta esse método é o parâmetro de potência ' $p$ ' (ISAAKS; SRIVASTAVA, 1989). E desse modo, antecedendo a aplicação desse método de estimativa, foram avaliados os parâmetros ' $p$ ' de valores 2, 3 e 4 . Como resultado, o parâmetro 4 , embora busque resultados mais distantes que com a aplicação dos valores 2 e 3 , apresentou resultados com menores variações dos valores observados nos poços tubulares.
- No método Triangulação, são geradas superfícies formadas por triângulos onde são utilizados para construção de um triângulo os três pontos mais próximos, de modo que nessa superfície não sejam gerados triângulos sobrepostos e que sejam os mais compactos possíveis (QGIS, 2020).

- No método Topo to Raster, é utilizado o método de diferenças finitas, onde uma célula de maior tamanho que a atribuída pelo usuário é utilizada para em seguida ser diminuída em resoluções menores até a definida pelo mesmo (MARCUZZO et al., 2011). Para aplicação desse método foi retirada a imposição de drenagem como fator na interpolação pois com essa aplicação são inferidas linhas de drenagem através do mais baixo ponto em cunha na área de drenagem circundando baixos incertos (ESRI, 2019).

A Triangulação busca informações mais próximas para a estimativa, enquanto os métodos Topo to Raster e Inverso da Distância Ponderada podem utilizar pontos mais distantes, embora seja possível escolher a proximidade da busca de acordo com o parâmetro de potência no interpolador IDW. Na Tabela 2 são descritas as principais características, vantagens e desvantagens dos interpoladores e, na Figura 2 as equações utilizadas em cada método e suas componentes são apresentadas.

Tabela 2 - Tabela apresentando os princípios, vantagens e desvantagens dos interpoladores

\section{Inverso da Distância Ponderada}

Estima valores em pontos sem amostragem usando a distância e os valores de pontos próximos conhecidos. A suposição é que os pontos amostrados mais próximos do ponto sem amostragem são mais semelhantes a ele do que aqueles mais distantes em seus valores.

Intuitivo, eficiente e de rápido processamento.

\section{Topo to Raster}

Estima os valores usando a repetição do método de diferenças finitas, onde são criadas grades estruturadas. 0 método busca atingir resoluções cada vez melhores com o processo, começando de uma grade inicial larga até uma grade que tenha resolução def nida pelo usuário.

Eficiência de interpolação local e global, e de rápido processamento.

\section{Triangulação}

Estima valores com a criação de uma superfície formada por triângulos a partir de pontos vizinhos mais próximos. Para fazer isso, círculos circunscritos são inseridos em volta dos pontos amostrais, então, suas intersecções são conectadas por uma rede de triângulos não sobrepostos e os mais compactos possíveis.

Intuitivo e de rápido processamento.

Os dados de entrada (contorno ou ponto) podem ser muito densos ou muitos espaçados para o tamanho da Superfícies não são suaves e geralmente pode não ser capaz de determinar um valor para essa célula. célula de saída especificado. Se uma célula de saída cobre vários contornos ou pontos de entrada, o algoritmo não é adequado para extrapolação para além da área com pontos amostrais coletados. pontos observados. 
Figura 2 - Métodos de interpolação e seus componentes: (A) Inverso da distância ponderada, (B) Triangulação, (C) Topo to Raster. Os pontos vermelhos indicam o valor a ser encontrado pelo método de interpolação e os pontos pretos indicam o ponto conhecido e utilizado na estimativa.

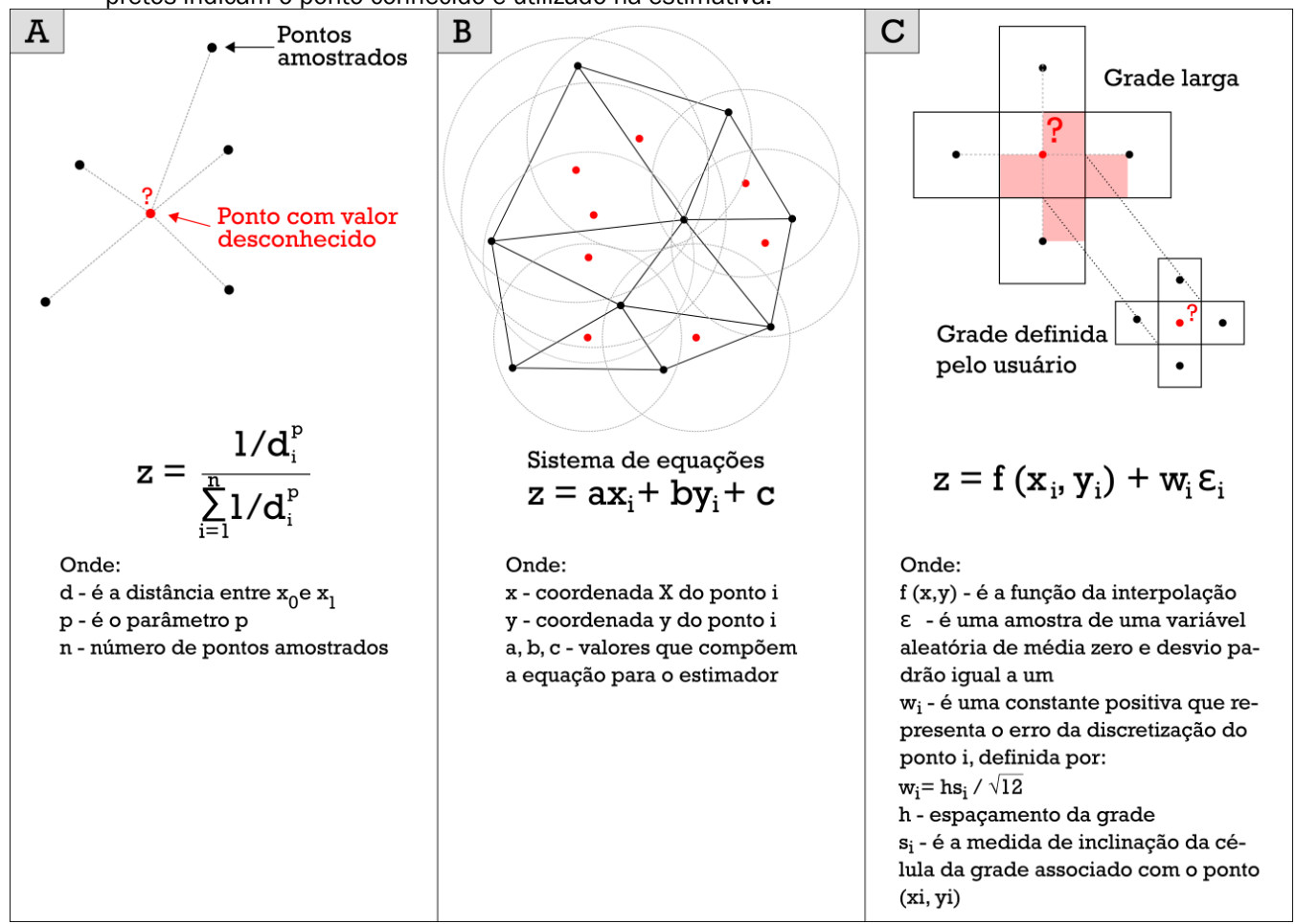

Fonte: Modificado de ISAAK \& SERIVASTER (1989); MARCUZZO et al. (2011); QGIS (2020)

A escolha do tamanho de célula de $200 \mathrm{~m}$ x $200 \mathrm{~m}$ foi baseada no espaçamento médio entre os pontos, utilizando como princípios o exposto por Hengl (2006) e Rossiter (2000) para definir o tamanho de célula ideal.

- Inverso da distância ponderada: pontos como dados primários de entrada; coeficiente $\mathrm{p}$ de valor 4; tamanho de célula de $200 \mathrm{~m}$ x $200 \mathrm{~m}$.

- Triangulação: pontos como dados primários de entrada; método de interpolação linear; tamanho de célula de $200 \mathrm{~m} \times 200 \mathrm{~m}$.

- Topo to raster: pontos como dados primários de entrada tamanho de célula de $200 \mathrm{~m}$ x 200m; sem imposição de drenagem.

\subsection{Análise da interpolação}

A baixa densidade de poços com informações hidrogeológicas limita tanto o método de avaliação dos resultados como os métodos de interpolação. Assim, a avaliação buscou a maior confiança dos resultados com o estudo das variações entre os valores observados e estimados.

Foram calculados os resíduos, que são a diferença entre os valores observados dos valores estimados (Eq. 1) e a porcentagem da variação entre eles (Eq. 2).

$$
r=v^{\prime}-v
$$

$$
p v=\left(\frac{\left(v^{\prime}-v\right)}{v}\right) * 100
$$

Onde: $r$ é o valor do resíduo, $v$ 'é o valor estimado, $v$ é o valor observado e $p v$ é a variação percentual entre os valores observados e estimados.

Os resultados foram analisados observando as seguintes situações:

a) Quantidade de dados utilizados pelo interpolador na estimativa;

b) Precisão do interpolador ao gerar variações próximas a zero porcento ( $0 \%)$;

c) Superestimativas (aumento dos valores) e subestimativas (redução dos valores), quando as variações eram superiores a $10 \%$;

d) Menores valores de Root Medium Square (RMS) normalizado.

A análise da interpolação gerou gráficos e tabelas. Nelas são apresentados os comportamentos de cada parâmetro em cada interpolador, com a indicação dos dados com aumento ou redução dos valores observados, além das estimativas tendenciosas (redução ou aumento superior a $10 \%$ do valor observado). As estimativas tendenciosas foram consideradas como àquelas em que os valores estimados variaram mais que $10 \%$ dos valores observados - superestimados quando os valores aumentaram e subestimados quando os valores diminuíram. 


\section{RESULTADOS E DISCUSSÃO}

Com relação à interpolação dos parâmetros, o interpolador IDW apresentou bons resultados, com menores variações entre os valores observados e os valores estimados. O RMS normalizado foi o menor para esse interpolador na maioria dos parâmetros e a única exceção foi no Aquífero Furnas, em que o Topo to Raster apresentou valores menores que o IDW nos parâmetros vazão e nível estático. Os valores de RMS normalizado mais elevados ocorreram quando foi aplicado o interpolador Topo to Raster nos parâmetros de condutividade hidráulica e transmissividade (Figura 3).

Figura 3 - Root Medium Square (RMS) normalizado para os parâmetros avaliados de acordo com os aquíferos

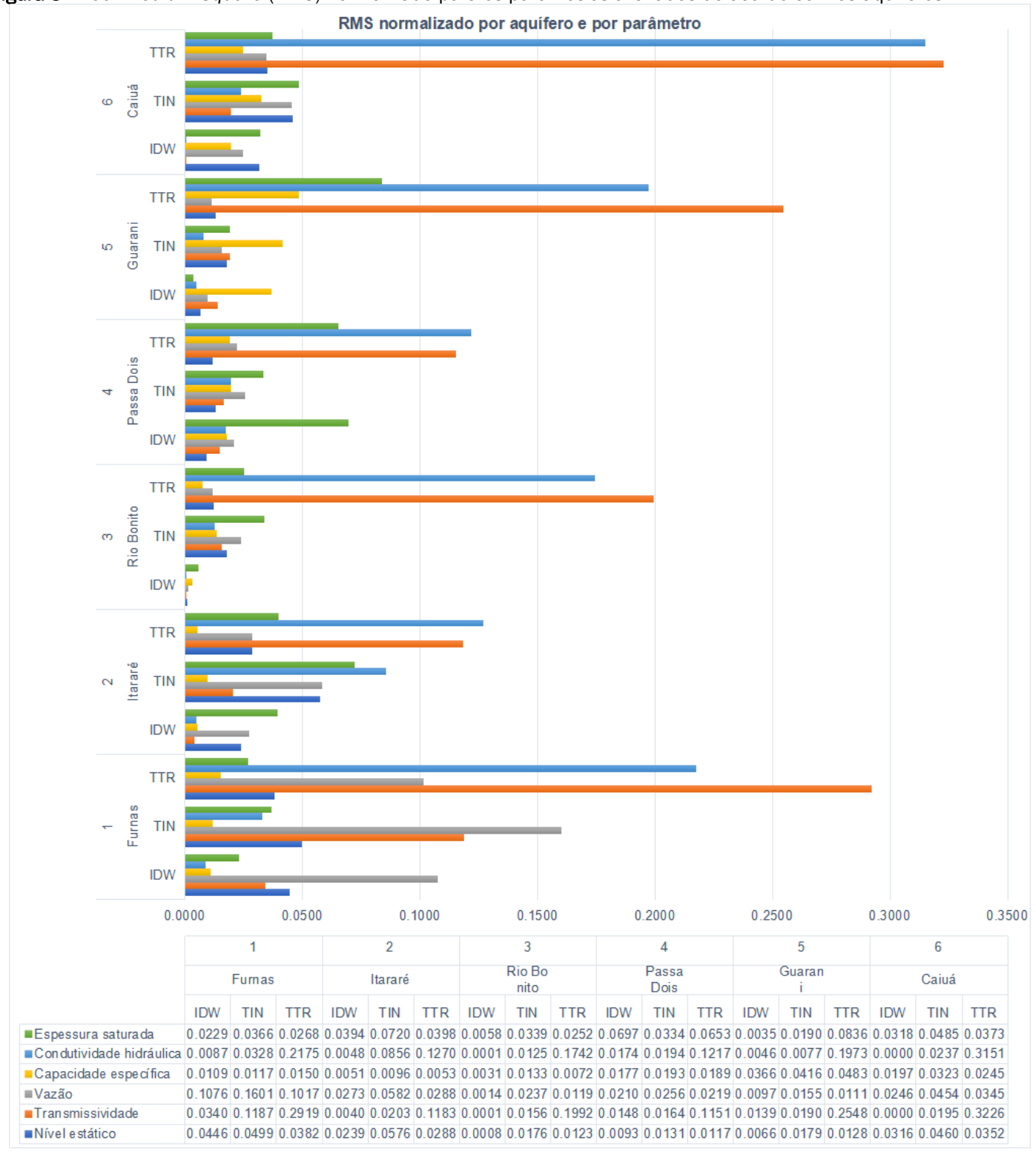

O que se observa é a variação entre regiões de altos, médios e baixos valores não coincidirem entre variáveis que foram calculadas utilizando o mesmo parâmetro, como é o caso da vazão (Q) e capacidade específica (qs), e espessura saturada (b) e profundidade do nível estático (NE).

O cálculo do parâmetro capacidade específica (qs) é realizado através da razão entre a vazão e o rebaixamento do nível d'água ( $\Delta S$ ) obtido no teste de bombeamento (Eq. 3). Assim, o valor do rebaixamento foi o que influenciou primeiramente nesse resultado, sendo que outros fatores locais, como geologia e estruturas (como falhas, fraturas e intrusões ígneas) podem ter influenciado nessa questão. Os mapas dos parâmetros de capacidade específica e vazão podem ser observados na Figura 4.

$$
q s=\frac{Q}{\Delta \mathrm{S}} \quad\left(\mathrm{m}^{3} \mathrm{~h}^{-1}\right) \mathrm{m}^{-1}
$$


Figura 4 - Mapas dos parâmetros capacidade específica e vazão utilizando o interpolador IDW nos dados do aquífero Caiuá Mapas de capacidade especíica (a) e vazão (b) do aquifero Caiuá através do método IDW

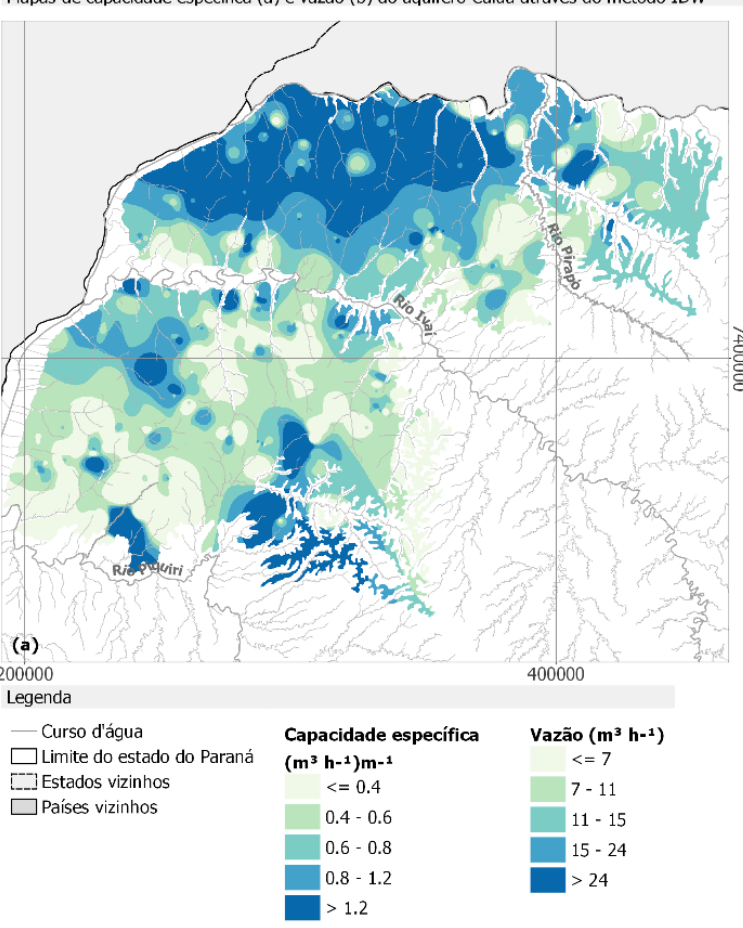

A espessura saturada (b) foi calculada através da diferença entre a profundidade do poço e o nível estático (NE) (Eq. 4). Entre essas duas variáveis também ocorre essa diferença de regiões e, nesse caso, a influência foi da profundidade do poço. Cabe um adendo, que em alguns poços do Aquífero Guarani o valor da espessura saturada considerado é equivalente à espessura perfurada dentro da unidade. Além disso, esses

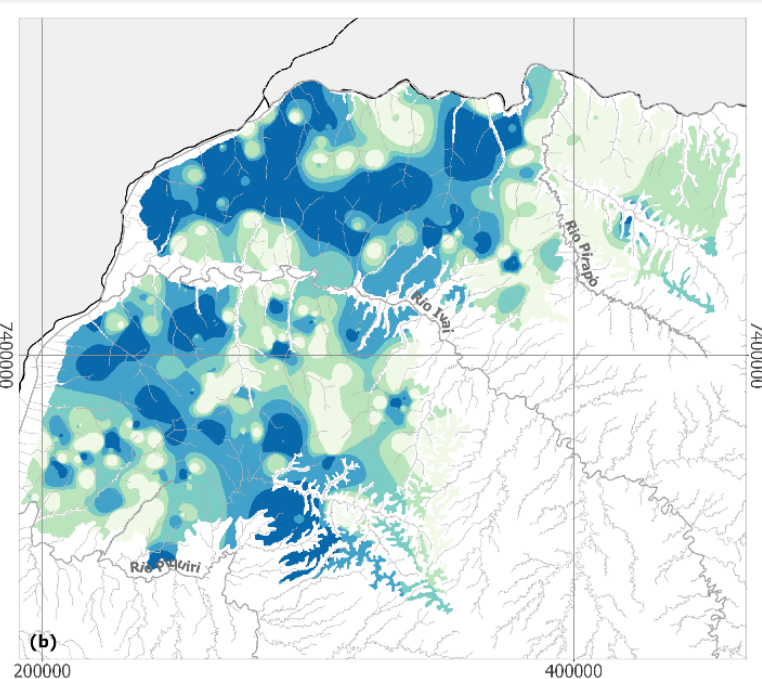

200000

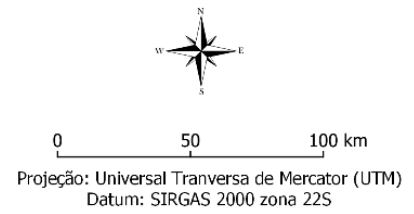

parâmetros podem ser influenciados por fatores locais, como geologia e estruturas (como falhas, fraturas e intrusões ígneas). Os mapas dos parâmetros de espessura saturada e nível estático podem ser observados na Figura 5.

$b=$ Profundidade do poço $-N E \quad(\mathrm{~m})$

Figura 5 - Mapas dos parâmetros espessura saturada e nível estático utilizando o interpolador IDW nos dados do aquífero Caiuá Mapas da espessura saturada (a) e nivel estático (b) do aquifero Caiuá através do método IDW

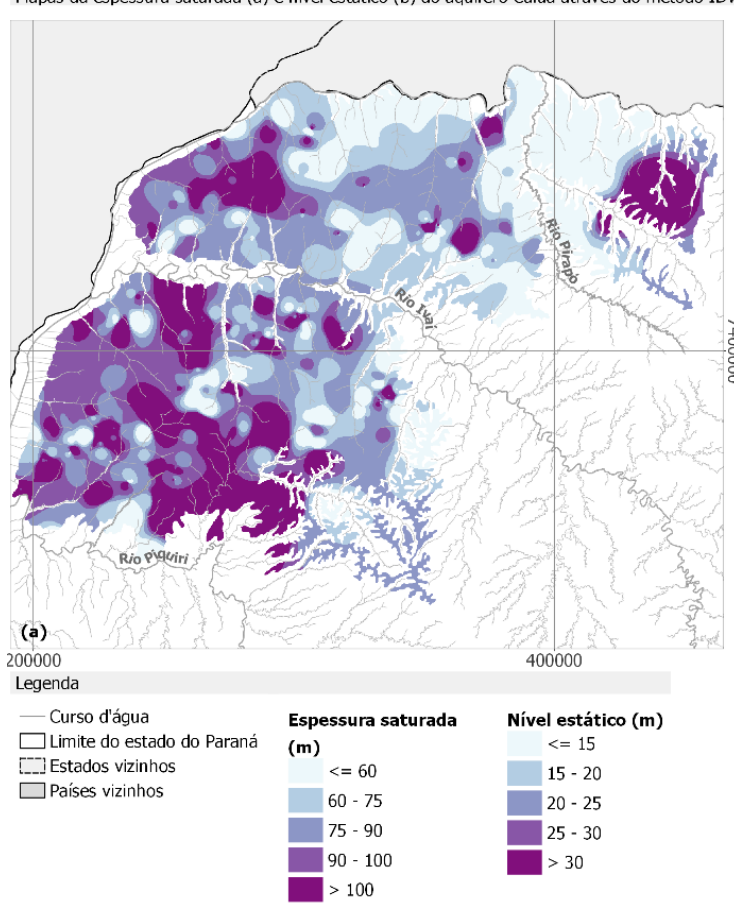

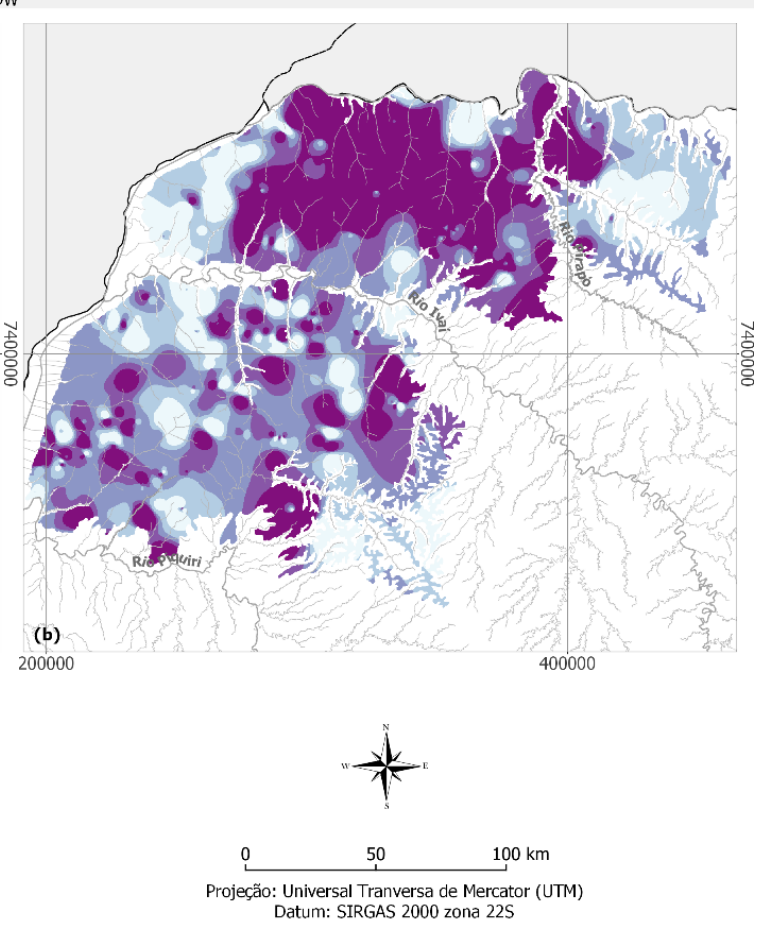


A transmissividade $(\mathbf{T})$ dos aquíferos foi calculada mediante análise de testes de bombeamento com mais de 12 horas de duração e o método utilizado foi o de Jacob (1950), de acordo com o livro Carta das Águas Subterrâneas do Paraná (BRASIL, 2015) (Eq. 5). A condutividade hidráulica (K) foi calculada dividindo a transmissividade $(\mathbf{T})$ pela espessura saturada (b) (Eq. 6). Essas duas variáveis não apresentam a variação que foi observada nas demais e quando ocorriam eram em áreas menores (Figura 6).

$$
\begin{array}{ll}
T=\frac{(0,183 * Q)}{\Delta \mathrm{S}} & \left(\mathrm{m}^{2} \mathrm{~s}^{-1}\right) \\
K=\frac{T}{b} & \left(m \mathrm{~s}^{-1}\right)
\end{array}
$$

Como exemplo da rotina utilizada são apresentados os mapas de capacidade específica (qs) dos aquíferos em estudo de modo a elucidar o efeito e conclusões que podem ser tomadas de acordo com os métodos de interpolação abordados (Figura 7).

Figura 6 - Mapas dos parâmetros transmissividade e condutividade hidráulica utilizando o interpolador IDW nos dados do aquífero Caiuá Mapas de transmissividade (a) e condutividade hidráulica (b) do aquifero Caiuá através do método IDW

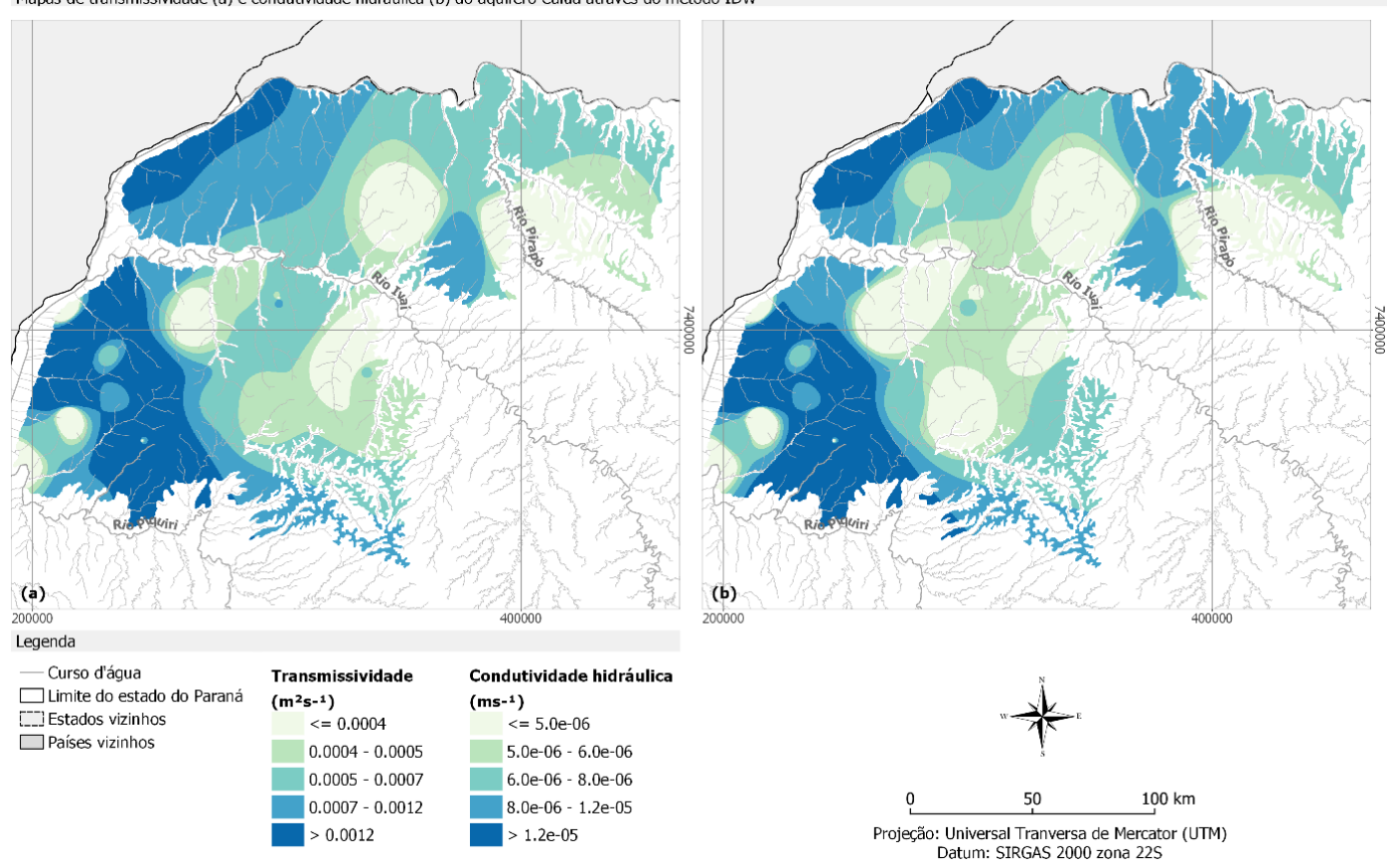

Figura 7 - Mapa do parâmetro capacidade específica dos interpoladores IDW, TIN e Topo to Raster Mapas de capacidade específica - Interpoladores (a) IDW, (b) TN e (c) Topo to Raster
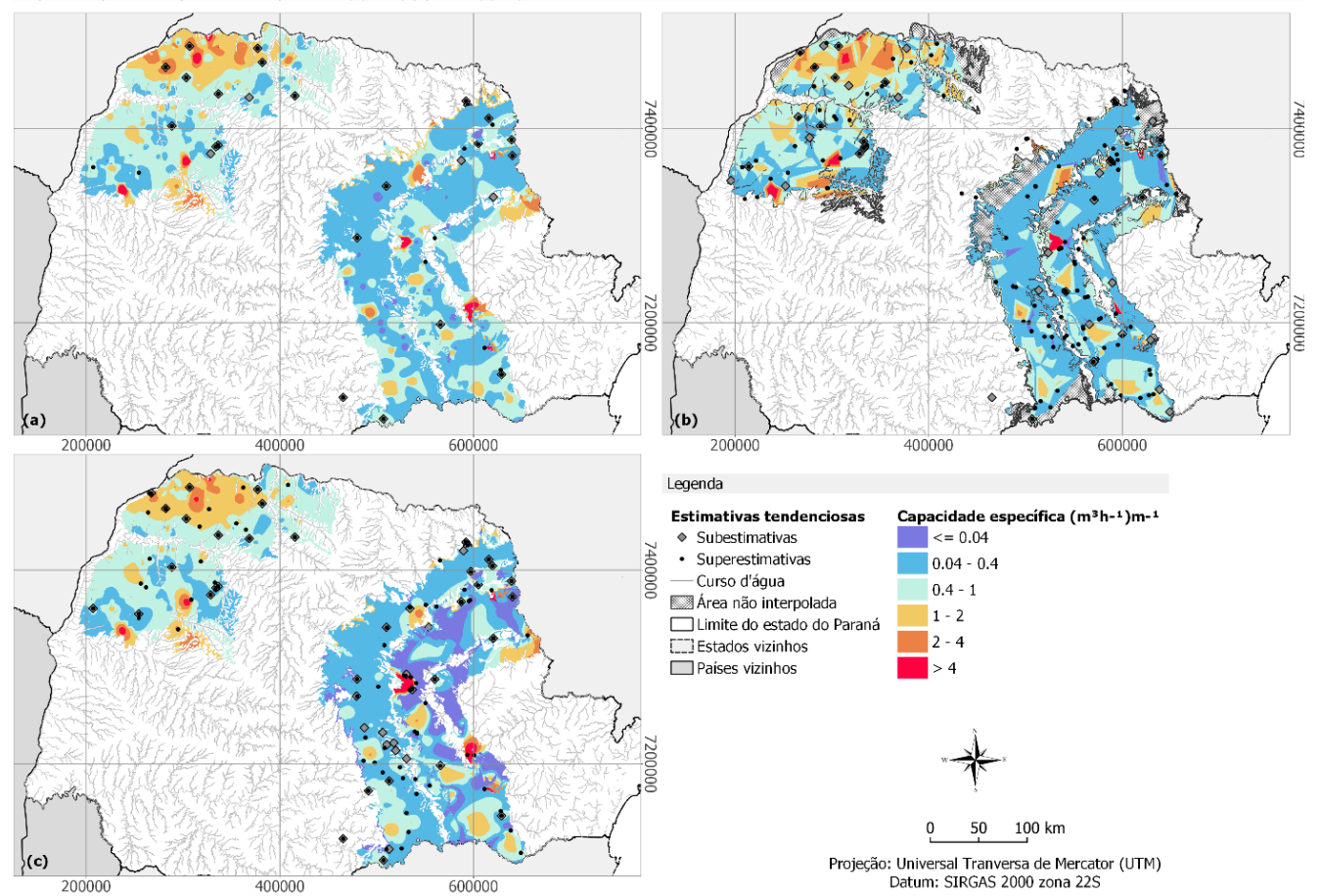

Legenda

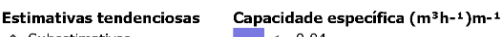

$\diamond$ Subestimativas

- Superestimativa

- Superestimatios

- Cursoa dão ina

$\square$ Limite do estado do Paraná

Estados vizinhos

$\square$ Paises vizinhos

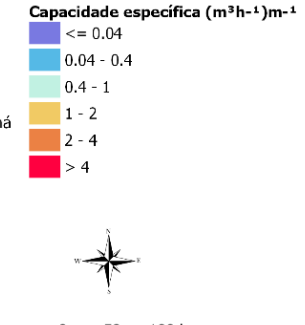

$0 \quad 50 \quad 100 \mathrm{~km}$

Projeçăo: Universal Tranversa de Mercator (UTM) Datum: SIRGAS 2000 zona 22S 
A análise da interpolação gerou os gráficos da Figura 8. Nessa figura são apresentados os comportamentos de cada parâmetro em cada interpolador, com a indicação do número de dados que se comportaram com valores acima (estimativas po- sitivas) e com valores abaixo (estimativas negativas) dos valores observados, além daqueles que apresentaram estimativas tendenciosas.
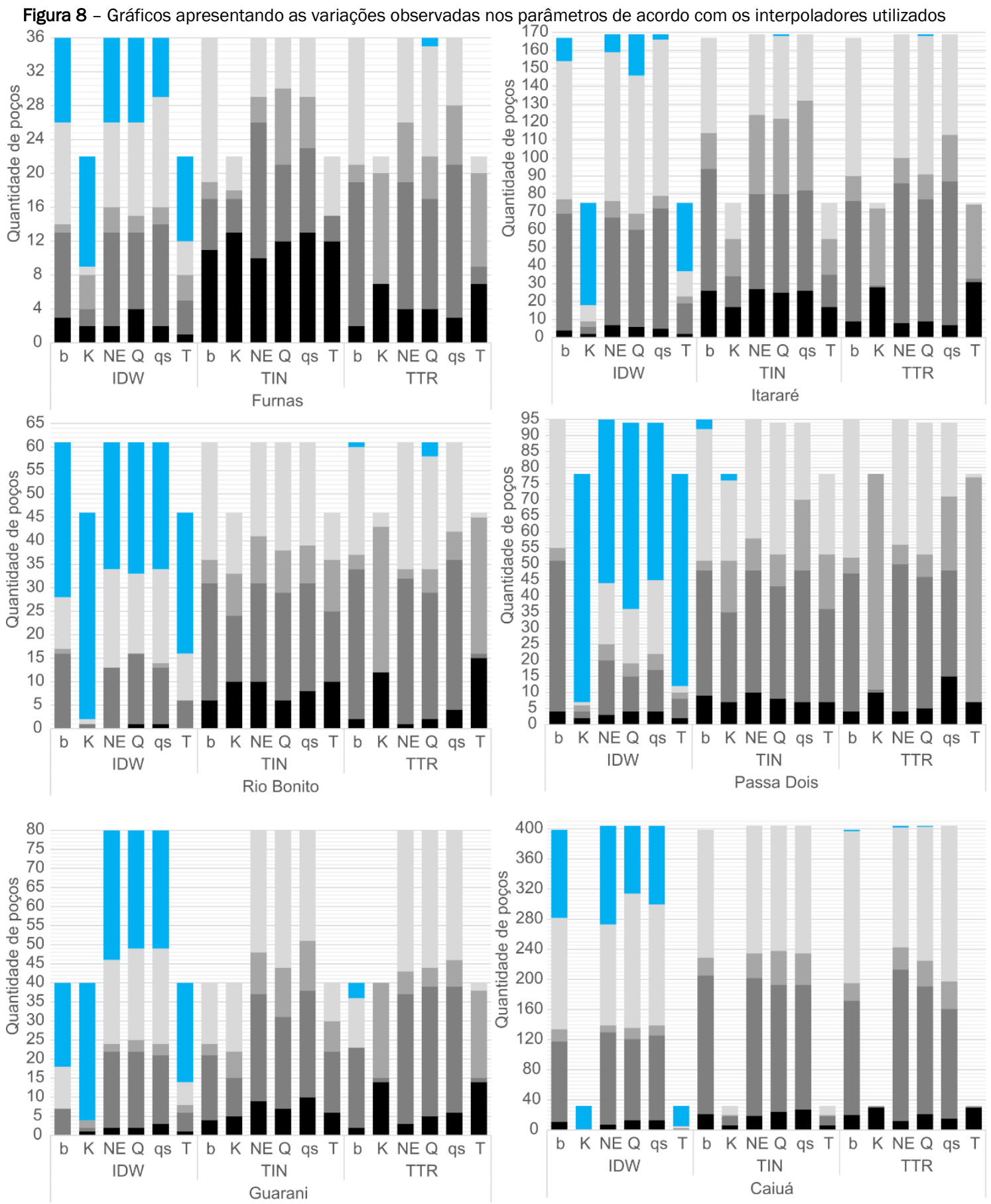

\section{Legenda}

- Sem variação $(p=0 \%)$

Estimativa positiva ( $p>0 \%)$

- Superestimativa ( $p>10 \%)$

- Estimativa negativa $(\mathrm{p}<0 \%)$

- Subestimativa $(p<-10 \%)$ 
As superfícies geradas utilizando o interpolador IDW apresentaram o efeito conhecido como "mira" ou "bull's eyes", onde são geradas superfícies concêntricas ao redor dos pontos de estimativa. Todavia, os valores apresentados por esse interpolador foram melhores que os apresentados pelos outros interpoladores por apresentar menos estimativas tendenciosas e menores variações entre os valores observados e interpolados.

Visualmente, o interpolador Topo to Raster gerou superfícies mais suaves comparadas às superfícies geradas pelo interpolador IDW. No entanto, as variações entre os valores observados e os valores estimados são maiores, especialmente nos parâmetros de condutividade hidráulica e transmissividade, com a ocorrência de estimativas tendenciosas em até 90\% desses dados.

O método de interpolação TIN, além de não utilizar todos os dados no processo de estimativa, apresentou estimativas tendenciosas e maiores variações que os dois outros métodos avaliados.

Os resultados sem variações entre os valores observados e os valores estimados ocorreram em todos os parâmetros, com ocorrência entre $2 \%$ a $100 \%$ nos dados dependendo da variável. Ainda, baixos valores tenderam a aumentar e altos valores tenderam a diminuir, mas as menores variações ocorreram utilizando o interpolador IDW.

\section{CONSIDERAÇÕES FINAIS}

No estudo apresentado foram obtidos bons resultados para uma escala regional e o interpolador IDW foi o menos impreciso em todos os aquíferos e em todos os parâmetros hidrogeológicos, pois apresentou estimativas tendenciosas em apenas $7 \%$ dos dados, onde algumas estimativas tendenciosas ocorriam em poços de mesma localização para parâmetros diferentes e essa ocorrência de maiores erros em poços de mesma localização se deve a grandes variações dos valores dos poços próximos.

O interpolador Topo to Raster, embora tenha gerado superfícies mais suaves, resultou em uma maior quantidade de dados com estimativas tendenciosas comparado ao interpolador IDW. O TIN foi o método que gerou piores resultados, pois tem a característica de não extrapolar além do limite dos dados de entrada e resultou em maiores erros nas estimativas.

Tendo como base esse estudo, em que foi considerado um tamanho de célula de $200 \mathrm{~m}$, ficando subentendido que nessa área de $40.000 \mathrm{~m}^{2}$ a água subterrânea tem o mesmo comportamento, ainda assim, não se conhece nem 1\% (quantidade de poços pela área interpolada) da dinâmica hídrica subterrânea.

Ainda, a ocorrência de super e subestimativas podem levar a interpretações errôneas dos dados. Quando ocorrem superestimativas em dados de capacidade específica, por exem- plo, há um otimismo em encontrar uma região com maior potencial. Com a ocorrência de subestimativas nos mesmos dados a interpretação pode ser inversa.

\section{AGRADECIMENTOS}

Os autores agradecem à Coordenação de Aperfeiçoamento de Nível Superior (CAPES) pelo apoio financeiro, e à Universidade Federal do Paraná (UFPR) e ao Laboratório de Pesquisas Hidrogeológicas (LPH) pela infraestrutura e apoio institucional à pesquisa.

\section{REFERÊNCIAS}

AGÊNCIA NACIONAL DE ÁGUAS (ANA). Conjuntura dos Recursos Hídricos no Brasil: regiões hidrográficas brasileiras. Brasília - DF, 2014. Relatório Pleno - Edição especial.

BRASIL. Ministério do Meio Ambiente (MMA). Carta das águas subterrâneas do Paraná: resumo executivo. Brasília DF - MMA, 2015. Relatório Pleno - Edição especial.

CETESB. Aquífero Guarani. Disponível em: https://cetesb.sp.gov.br/aguas-subterraneas/programa-de-monitoramento/consulta-por-aquiferos-monitorados/aquifero-guarani/. Acesso em: 15 set. de 2020.

ESRI. Topo to Raster. Disponível em: https://desktop.arcgis.com/en/arcmap/10.5/tools/spatialanalyst-toolbox/topo-to-raster.htm. Acesso em: 03 maio 2019.

ESTAVARENGO, B.; CASTRO, B. Espacialização de dados de infiltração obtidos com o permeâmetro de Ghelph: estudo de caso no Instituto Federal do Tocantins. Monografia (Graduação) - Universidade Federal do Tocantins, 2017.

FEITOSA, F. A. C. et al. Hidrogeologia: conceitos e aplicações. [S.I.]: CPRM, 2008.

FERNANDES, L. A. A cobertura cretácea suprabasáltica no Paraná e Pontal do Paranapanema (SP): os grupos Bauru e Caiuá. Tese (Doutorado) - Universidade de São Paulo, 1992.

FERNANDES, L. A.; COIMBRA, A. M. Revisão estratigráfica da parte oriental da Bacia Bauru (Neocretáceo). Revista brasileira de Geociências, v. 30, n. 4, p. 717-728, 2000. https://doi.org/10.25249/0375-7536.2000304717728

FRANÇA, A. B.; POTTER, P. E. Estratigrafia, ambiente deposicional e análise de reservatório do Grupo Harare (Permocarbonífero), Bacia do Paraná. i. Boletim de Geociências da PETROBRÁS, v. 2, n. 2-4, p. 147-191, 1988.

HENGL, T. Finding the right pixel size. Computers \& geosciences, Elsevier, v. 32, n. 9, p. 1283-1298, 2006. 
IBGE. Cidades e estados. Disponível em: https://www.ibge.gov.br/cidades-e-estados.html. Acesso em: 25 out. 2020. https://doi.org/10.1016/j.cageo.2005.11.008

ISAAK, E.; SERIVASTER, R. An introduction to applied geostatistical, 561 oxford: Oxford university press. 1989.

KUMAR, P. et al. Mapping of groundwater potential zones in Killinochi area, Sri Lanka, using GIS and remote sensing techniques. Sustainable Water Resources Management, Springer, v. 2, n. 4, p. 419-430, 2016 https://doi.org/10.1007/s40899-016-0072-5

LI, J.; HEAP, A. D. A review of spatial interpolation methods for environmental scientists. Geoscience Australia Canberra, 2008.

MARCUZZO, F. F. N.; ANDRADE, L. R.; MELO, D. C. d. R. Métodos de interpolação matemática no mapeamento de chuvas do estado do Mato Grosso. 2011.

MELO, M. S. D.; GOMES, R. M.; PEREIRA, G. K. Água subterrânea no gráben de Ponta Grossa, pr. Boletim Paranaense de Geociências, v. 72, 2015. https://doi.org/10.5380/geo.v72i0.35937

MILANI, E. et al. Bacia do paraná. Boletim de Geociências - Petrobras, v. 15, p. 265-287, 012007. https://doi.org/10.25249/0375-7536.1985287292
PINTO, D. et al. Delineation of groundwater potential zones in the Comoro watershed, Timor Leste using GIS, remote sensing and analytic hierarchy process (ahp) technique. Applied Water Science, Springer, v. 7, n. 1, p. 503-519, 2017. https://doi.org/10.1007/s13201-015-0270-6

QGIS. Análise Espacial (Interpolação). Disponível em: https://docs.agis.org/2.14/en/docs/gentle_gis_introduction/spatial analysis interpolation.html. Acesso em: 15 set. 2020.

RIBEIRO, D. D. de M. et al. Definição de áreas potenciais para a ocorrência de água subterrânea na sub-bacia do Rio Siriri-Sergipe com o auxílio do ahp (método analítico hierárquico). Águas Subterrâneas, 2010.

ROSA FILHO, E. F. da R. Aquíferos do Estado do Paraná. Curitiba, PR: Edição do autor, 2011.

ROSSITER, D. Methodology for soil resource inventories, 2nd revised version. Soil Science Division, International institute for Aerospace Survey \& Earth Science (ITC), 2000.

SCHNEIDER, R. et al. Revisão estratigráfica da Bacia do Paraná. In: CONGRESSO BRASILEIRO DE GEOLOGIA, 28., 1974. [Anais...]. [S.I.: s.n.], p. 41-65, 1974. 